\title{
DOSSIÊ TEORIA CRÍTICA E EDUCAÇÃO NA ATUALIDADE: OLHARES PLURAIS (APRESENTAÇÃO)
}

\section{O Dossiê Teoria Crítica e Educação}

na atualidade: olhares plurais, foi organizado pelos professores Luzia Batista de Oliveira Silva - PPGSSE/USF Alex Sander da Silva - PPGE/UNESC e Allan da Silva Coelho; é uma contribuição de pesquisadores da Teoria Crítica da Sociedade para o campo da Educação no Brasil; contou com a participação de quatorze pesquisadores de diversas áreas do conhecimento, instituições, estados e cidades num total de nove artigos.

Ana Carolina Kastein Barcellos, no artigo $O$ uso do smartphone e a construção de sentido, apresenta os embates e discute as perspectivas sobre a atualidade do conceito de indústria cultural para analisar o uso do smartphone e seus derivados na relação com a compreensão leitora $e$ a construção de sentido. A autora questiona em sua pesquisa se é possível ao sujeito fazer uma leitura, de forma crítica e dialética com o uso do smartphone e seus derivados, e em que medida, isso poderia ocorrer? A hipótese da pesquisa é que, ao realizar a leitura no aparato, a palavra perde relevância comparada à imagem que é percebida, visualizada, mais do que pensada/entendida e o seu conceito se reduz a uma função icônica. Por isso, o campo semântico se limita a associações automáticas e, dessa forma, operacionalizam-se as leituras. A pesquisa empírica realizada foi desenvolvida com a participação de estudantes com idades entre 17 e 19 anos, ou seja, que já concluíram a educação básica e ingressaram em uma universidade. $\mathrm{O}$ instrumento de pesquisa aplicado foi uma questão escrita a partir de uma charge com um assunto vinculado ao dia a dia dos participantes e, uma entrevista previamente formulada. Toda a pesquisa foi aplicada no espaço acadêmico.

\section{Ângela Maria Pires Caniato, Mônica} Salci Palelasso e Naira Valdelaine Balduino, no artigo $A$ construção identitária dos adolescentes pobres de periferia na era da sociedade de consumo e da indústria cultural, dissertam sobre conceitos como reciprocidade dialética entre indivíduo e cultura, a partir das demarcações dos campos da Psicanálise freudiana e da Teoria Crítica da Sociedade de Adorno e Horkheimer. As indagações apresentadas pelas autoras, decorreram de um trabalho desenvolvido com adolescentes pauperizados de uma escola estadual da rede pública de ensino de Ma-

SILVA, Luzia Batista de Oliveira; SILVA, Alex Sander da; COELHO, Allan da Silva. Dossiê Teoria Crítica e Educação na atualidade: olhares plurais (Apresentação). Revista Sul-Americana de Filosofia e Educação. Número 29: nov./2017-abr./ 2018, p. 1-4. DOI: https://doi.org/10.26512/resafe.v0i29.21001 
ringá/PR. Os encontros foram realizados no primeiro semestre de 2016 pelos discentes da graduação e pós-graduação integrantes do projeto de ensino e extensão "Phenix - a ousadia do renascimento do indivíduosujeito - fase $I V$ ', vinculado à Universidade Estadual de Maringá, no estado do Paraná.

Danielle Regina do Amaral Cardoso, no artigo Teoria Crítica, Sociedade e Educação: reflexóes sobre as tensóes da era tecnológica na infância. Traz uma reflexão sobre as tensões provocadas pela forte presença das tecnologias e o crescente progresso técnico na formação das crianças. Em meio a uma infância tecnológica, há uma melancolia em função da priorização do apego às máquinas em detrimento das relações humanas. Trata-se de uma análise proveniente de uma tese de doutorado embasada na Teoria Crítica, com a contribuição de autores afins.

Darlan Marcelo Delgado e Luiz Roberto Gomes, no artigo Teoria Crítica e a gestão social da educação: reflexões a partir da teoria do agir comunicativo de Habermas, apresentam o conceito de gestão social, fundado na Teoria do Agir Comunicativo de Habermas, como forma de reflexão crítica sobre a Administração Educacional Tradicional. Vislumbram-se possibilidades em se pensar uma concepção de adminis- tração educacional voltada à formação plena, de sujeitos autônomos e emancipados, preparados para o trabalho, para a vida $e$ para a ação política esclarecida.

Estelamaris Brant Scarel, no artigo $A$ Teoria Crítica da Sociedade e a Educação para a Formação Humana: pontuações para se repensar os processos formativos na perspectiva emancipatória, centrou suas análises a partir dos pensadores frankfurtianos - Adorno e Horkheimer, na obra "Dialética do Esclarecimento" (1985), com referência à promessa de iluminação da razão, que, contraditoriamente, transformou-se em um malogro, em virtude de as relações entre os homens em sociedade pautarem-se pelo viés da racionalidade científicoinstrumental, levaram o presente texto a deter-se em três objetivos específicos. Primeiramente, ele procura trazer à tona alguns elementos fundamentais contidos na obra acima aludida, os quais possibilitam o entendimento de que a limitação da filosofia pela sua rendição à ciência se deve, principalmente, à fragilização da capacidade reflexiva. Em segundo lugar, busca fazer uma aproximação aos conceitos de educação, formação e experiência formativa, tentando, simultaneamente, apreender os nexos que conduziram à ruptura, na modernidade, entre sujeito e objeto, universal e par- 
ticular, teoria e práxis. Em terceiro e último lugar, põe em relevo os desafios postos à educação contemporânea no que concerne à premência de ela recuperar o processo formativo, mediante o desenvolvimento de uma educação para a experiência, por conseguinte, para a emancipação.

Ingrid Anastácia de Sousa, Carolina Machado Saraiva de Albuquerque Maranhão e Rosany Cecília de Sena no artigo $A$ Reificação da Cultura: Uma Análise do Programa de Educação Patrimonial do Trem da Vale sob a ótica da Indústria Cultural, discutem como a mineradora Vale S.A., ativamente atuante na região de Mariana $e$ Ouro Preto, no Estado de Minas Gerais, idealizou um projeto direcionado à Educação Patrimonial que durante 8 anos foi considerado como um dos principais projetos com viés cultural da região. Neste contexto, considerando que a Educação Patrimonial é de extrema importância para a formação da identidade cultural e social do indivíduo autônomo, objetivou-se analisar, sob a perspectiva crítica, as inter-relações entre o Programa de Educação Patrimonial Trem da Vale com o conceito que carrega a Indústria Cultural, conforme cunhado pelos teóricos críticos Theodor Adorno e Max Horkheimer no livro "Dialética do Esclarecimento" (1985). Para a realização da aná- lise empírica utilizou-se como categoria de sentido a tese de Francisco Rüdiger (2004) sobre os esquematismos interpretativos comumente presentes nas práticas da Indústria Cultural.

\section{Maria Isabel Formoso Cardoso e} Silva Batista, no artigo Teoria crítica e formação do indivíduo: consideraçôes sobre a análise crítico-dialética da relação entre subjetividade e objetividade na contemporaneidade, tece algumas considerações sobre a formação do indivíduo e reflete sobre a necessidade de uma análise crítica sobre os elementos e os processos formativos contemporâneos respaldada no método dialético, apoiado nos fundamentos da Teoria Critica da Sociedade e nos princípios psicanalíticos, a fim de que se possam apreender as contradições sociais presentes na relação sujeito-objeto/indivíduo-sociedade. Por meio da reflexão sócio histórica, inerente ao método dialético, o movimento histórico da realidade social é apreendido teórica e conceitualmente, conduzindo à compreensão da relação entre subjetividade e objetividade como reciprocamente mediada, tendo-se a subjetividade como fruto de um projeto histórico e paradoxal da civilização ocidental. Assim, analisar criticamente a formação do indivíduo na contemporaneidade significa considerar as tendências $e$ as contradi- 
ções desenvolvidas ao longo do processo histórico, que produziram certos elementos presentes no contexto social e cultural da atualidade, os quais se interligam $e$ incidem diretamente sobre os processos formativos, de modo a determiná-los.

Nilo Agostini, no artigo Educação, bioética e cidadania: aproximaçôes, convergências e transversalidades na perspectiva da teoria crítica, na sua investigação teórica, tece convergências e transversalidades entre educação, bioética e cidadania, através de algumas de suas interfaces. Parte do diálogo em construção entre os sujeitos ativos nestes campos. Assim, a educação investe no sujeito $e$, permeada pela ética, tece aproximações e identifica transversalidades com a bioética e a cidadania, apostando sempre na emergência do sujeito ético. Capaz de ação e reflexão - ser da práxis - este sujeito investe na transformação da realidade e de si mesmo. Faz da bioética um campo de diálogo que prima pela vida, com atenção à saúde pública. Foca a cidadania como construção histórica, na conquista, incorporação e consolidação de direitos, como é o da saúde. Investe na emancipação dos sujeitos e comunidades, capazes de uma autorreflexão crítica, de assumir compromissos históricos e de buscar alternativas no conjunto da vida social.
Thaís Lobosque Aquino, no artigo Saber musical sensivel nas escolas de educação básica brasileiras: perspectivas, dimensões e fundamentos, disserta a respeito das perspectivas, dimensões e fundamentos do saber musical sensível em escolas de educação básica brasileiras. Parte constituinte de uma pesquisa teórica voltada a pensar a epistemologia da educação musical escolar (AquiNo, 2016), tem-se como pressuposto o fato de o saber musical escolar ser um tipo de saber sensível e, como tal, capaz de fomentar modos de operar articuladores de aspectos comumente percebidos como incompatíveis $e$, por conseguinte, apreendidos e vivenciados de forma dissociadora na contemporaneidade. À medida que são estabelecidas as relações imanentes entre seus fundamentos éticos, cognitivos, emocionais e somáticos, suas dimensões científicas, filosóficas e artísticas, bem como as relações extrínsecas com outros campos do saber, acredita-se contribuir para a construção de alicerces epistemológicos mais claros para a educação musical nas escolas brasileiras de educação básica.

\section{Luzia Batista de Oliveira Silva Alex Sander da Silva Allan da Silva Coelho}

